\title{
Em busca de "likes": A influência das mídias sociais no comportamento do consumidor no consumo de viagens
}

\author{
Francisco Wilker Carneiro Brito* \\ Ana Augusta Ferreira de Freitas**
}

Universidade Estadual do Ceará (Brasil)

\begin{abstract}
Resumo: A constante evolução das redes sociais tem gerado importantes reflexões a respeito das relações interpessoais na contemporaneidade. Tal temática se faz cada vez mais pertinente para o campo cientifico, uma vez que tem impactado diretamente diferentes indivíduos e setores econômicos. Nessa seara, o presente estudo tem por objetivo compreender de que forma o consumo de destinos turísticos é influenciado pela interação e compartilhamento de experiências que ocorre nas redes sociais. Assim, realizou-se uma pesquisa qualitativa, utilizando-se entrevistas em profundidade com técnicas projetivas, que identificou as mídias sociais como mediadoras da construção da identidade e da busca por popularidade, o desejo de auto exposição e a necessidade de aprovação como fatores motivadores para a escolha do destino turístico e para o compartilhamento de experiências de viagens. Tais achados, vão além dos construtos já abordados na literatura de turismo e marketing que vinculam a influência das redes sociais ao comportamento do consumidor.
\end{abstract}

Palavras-chave: Mídias Sociais; Consumo de Viagens; Compartilhamento de experiências; Self; Identidade.

\section{In search of "likes": The influence of social media on consumer behavior in travel consumption}

Abstract: The evolution of social networks has generated important reflections on inter-personal relationships in the contemporary world. This theme is of great economic and socio-cultural importance in tourism. The present study aims to understand the interactive consumption of shared experiences on the social networks and its influence on tourist destinations. A qualitative study was carried out, using in-depth interviews and projection techniques, to identify how social media produce constructs of identity, the effects of the search for popularity, the desire of self-exhibit and, the need for approval as motivating factors for the choice of any one tourist destination and for sharing the travel experience. These analyses go beyond the constructs already studied in the literature on tourism and marketing that link the influence of social networks to consumer behavior.

Keywords: Social Media; Travel Consumption; Sharing experiences; Self; Identity.

\section{Introdução}

A crescente interatividade, proporcionada pelo crescimento das mídias sociais, torna válida a busca pela compreensão de como essas conexões em rede influenciam as relações de consumo (Patrocínio, 2012; Hu et al., 2016; Schultz, 2016). Nesse cenário, observa-se uma mudança no comportamento dos consumidores, que passam a ser importantes atores e tomadores de decisão, frente ao potencial acesso de informações que detêm (Sacchet et al., 2011). Em termos de pesquisa, os temas que destacam a relação de consumo e mídias sociais, tais como o consumo em ambientes on-line (Chen; Zhu; Xie, 2004), a comunicação boca a boca eletrônica (Phau; Lo, 2004; Tubenchlak, 2013), o boca a boca e o comportamento afetivo e, ainda, o boca a boca e as redes sociais (Brown; Broderick; Lee, 2007) são emergentes.

\footnotetext{
* Mestrando em Administração de Empresas pela Universidade Estadual do Ceará, UECE. Bacharel em Administração pela mesma instituição; E-mail: f.wilkerbrito@gmail.com

** Pós-Doutorado em Administração (EBAPE-FGV, 2011), Mestrado e Doutorado em Engenharia de Produção (UFSC, 1995 e UFSC (2000); E-mail: freitas8@terra.com.br
} 
O termo rede social é comumente utilizado para definir os ambientes sociais formados na Internet (Smith et al., 2008; Recuero, 2009; Kietzmann et al., 2011). De acordo com Recuero (2009), pode ser definido também como um conjunto de relações formadas entre atores e suas conexões, no qual, os atores são representados por pessoas, instituições ou grupos e as conexões são constituídas pelos laços sociais, formados através da interação social entre os atores. Nesse contexto, as redes sociais apresentam-se como um ambiente propício para, na esfera dos atores, o autogerenciamento da imagem pessoal e construção do "eu" e, no âmbito das conexões, fortalece-se como um espaço potencializador da busca por capital social (Recuero, 2009), aqui entendido como os benefícios que se recebe das relações com as outras pessoas (Lin, 1999).

Nessa seara, há uma faceta específica do efeito das mídias sociais no comportamento do consumidor ainda pouco explorada e que interessa para fins de desenvolvimento desse estudo: as mídias sociais enquanto meio de os indivíduos construírem sua identidade, a partir dos relacionamentos criados e das escolhas de consumo. O interesse acadêmico e gerencial pelo assunto decorre da sua relevância, dado o empoderamento dos consumidores na era das redes sociais (Pan; Maclaurin; Crotts, 2007), visto que é possível considerar que esses consumidores utilizam bens e serviços para dizer alguma coisa sobre si mesmo e reafirmar suas identidades, considerando seus pertences e experiências como parte deles, incorporando-os como uma extensão do self (Belk, 1988). Complementar a isso, a possibilidade da criação de múltiplos "eus" on-line é uma área promissora de pesquisa (Belk, 2016) e, dessa maneira, faz-se pertinente entender o impacto desse novo contexto no comportamento do consumidor (Stephen, 2016).

Dessa forma, para ilustrar essa faceta, o presente estudo tomará como base o setor de turismo, campo que possui uma cadeia de valor diretamente centrada nas decisões do consumidor final (Alves et al., 2009), o que faz crítico entender o impacto das mudanças tecnológicas no comportamento deste consumidor nesse setor (Xiang; Gretzel, 2010). Além disso, pesquisas recentes reconhecem que a Internet tem alterado profundamente a forma como os viajantes acessam as informações, planejam e compartilham suas experiências de viagem (Xiang; Gretzel, 2010; Camargo et al., 2016; Pinto, 2016; Serafim; Mendes; Corrêa, 2017). O ambiente on-line fornece a estes um conhecimento variado, possibilitando o acesso a informações e experiências de inúmeras pessoas (Phelan; Chen; Haney, 2013). Todavia, não é apenas a busca por informações a única dimensão na qual a Internet tem afetado este setor. É crescente o segmento de viajantes que passam a consumir experiências de viagens quase que inteiramente baseadas em quão "compartilháveis" elas são, ou quanto capital social elas têm capacidade de gerar nas redes sociais (Amadeus, 2017).

É a partir dessa inquietação que surge a pergunta de investigação central desse estudo: qual a influência da interação nas mídias sociais no consumo de destinos turísticos? De forma secundária, questiona-se: a ponderação acerca da possibilidade de compartilhar experiências de viagens nas redes sociais é considerada na escolha do destino turístico? O que os viajantes almejam ao compartilharem suas experiências de viagens com outros usuários das redes sociais? Qual impacto desse fato na construção da identidade desse indivíduo? Para atender esses anseios, o objetivo geral desta pesquisa é compreender de que forma o consumo de destinos turísticos é influenciado pela interação e compartilhamento de experiências que ocorrem nas redes sociais. Assim, na fundamentação teórica, seção seguinte, temas como capital social, vaidade e popularidade serão essenciais.

\section{Fundamentação teórica}

Diante da difusão e popularização dos meios de comunicação em massa, a Internet tem ganhado cada vez mais espaço, tornando-se um veículo impulsionador de autonomia aos seus usuários, estreitando a relação, até então das mídias convencionais, entre plateia e autores. No contexto atual, em vez de usar a internet exclusivamente como espectadores, para buscar notícias, informação ou cultura, os usuários passam a usá-la também como autores, de forma que passam a ser de fato a notícia, a informação e a cultura (Keen, 2007). Nesse cenário, é comum que os indivíduos se encontrem regularmente conectados uns aos outros (Oliveira; Frossard, 2017). Essa crescente interatividade, proporcionada pelo crescimento das redes sociais, tem promovido transformações capazes de impactar diferentes usuários e diversos setores econômicos (Machado, 2015).

As redes sociais ganharam relevância com o advento da Web 2.0, que se referia a uma nova geração de aplicações na Web, nas quais, em sua essência, buscava permitir que os usuários fossem mais ativos, possibilitando a construção coletiva de conhecimento (O'Reilly, 2007). Contudo, para definição de redes sociais há uma grande diversidade de conceitos e baixa similaridade entre esses. Para fins de desenvolvimento desse trabalho, o conceito de redes sociais a ser adotado considera estas como um tipo de mídia social que permite aos usuários se conectarem através da criação de perfis com informações pessoais, possibilitando a criação e a troca de conteúdos gerados pelos próprios usuários, promovendo assim interações contínuas (Boyd; Ellison, 2008; Kaplan; Haenlein, 2010). 
Quando se estabelece um perfil nas redes sociais, habitualmente os seus usuários são provocados a responderem a seguinte reflexão: “Quem é você?". Tal provocação possui um alto nível de complexidade, visto que, cada indivíduo tem uma imagem de si mesmo, com um conjunto de crenças, hábitos e comportamentos, resultante de vivências e experiências construídas ao longo da história de suas vidas (Schiffman; Kanuk, 2000). Nesse contexto, as apresentações em mídias sociais são normalmente utilizadas como suportes digitais para melhorar a auto apresentação do indivíduo, permitindo um autogerenciamento e cocriação do "eu", tendendo assim, a uma representação mais próxima de um self ideal do que o próprio self (Belk, 2016).

Essa concepção lança luz nos conceitos de self e identidade, no qual o self é o resultado de um processo de autorreflexão, à medida que o indivíduo se torna um objeto significativo para ele mesmo ao observar sua reflexividade a partir do ponto de vista do outro (Simon, 2004). A identidade, para além do processo de autorreflexão contido no self, se apresenta como um meio para comunicação deste para o mundo exterior, e precisa da aprovação do outro para se estabelecer de forma bem-sucedida (Bauman, 2005).

A capacidade de autogerenciamento do processo de construção da identidade do indivíduo nas redes sociais torna seus usuários mais propensos a incorporarem esses "novos eus", não só apenas como uma parte do self estendido, mas também como parte de si mesmo (Belk, 2016). Esse cenário demandou uma ampliação das noções teóricas sobre self estendido, anteriormente entendido como o composto de uma pessoa, mente, corpo, bens físicos, família, amigos, lugares e experiências, que por meio de suas possessões complementariam a formação do self (Belk, 1988). Adicionalmente a essa composição teórica, com o fortalecimento das redes sociais e a concepção de posses, que representa uma espécie de arquivo pessoal que permite ao indivíduo refletir sobre sua história (Belk, 1988), passa-se a levar em consideração o engajamento e a interação dos indivíduos com o mundo exterior no ambiente virtual (Belk, 2016).

O construto de self estendido envolve o comportamento do consumidor (Belk, 1998) e trouxe para essa área uma abordagem predominantemente interpretativista (Ladik; Carrillat; Tadajewski, 2015). $\mathrm{Na}$ concepção de Belk (1988), não se pode compreender o comportamento do consumidor sem primeiro obter uma compreensão dos significados que esses consumidores atribuem às suas posses. Logo, para entender o comportamento dos consumidores em contexto de redes sociais faz-se necessário compreender o processo de engajamento e interação dos usuários no ambiente on-line.

Neste contexto, é possível perceber que os indivíduos estão se expondo cada vez mais nas redes sociais (Stephen, 2016), tornando-se ao mesmo tempo os escritores, os produtores, os técnicos e, sim, os espectadores do seu próprio show (Keen, 2007). As motivações para compartilhar suas vidas são inúmeras e vão desde a preservação da memória de um momento vivido quanto o compartilhamento de experiências com os amigos (Ramanathan; McGill, 2007; Zauberman; Ratner; Kim, 2009). As pessoas motivadas a partilhar suas experiências, através de fotos nas redes sociais, podem tornar-se muito preocupadas com o gerenciamento de impressões e com a auto apresentação (Barash; Diehl; Zauberman, 2014). Assim, os indivíduos assemelham a uma "vitrine" disponível em tempo integral, tornando o desempenho em suas redes algo essencial na performance adotada nas plataformas virtuais (Sousa; Braga, 2015). Ações como "Curtir", "Compartilhar" e "Seguir" traduzem as relações entre pessoas, ideias e coisas em algoritmos, a fim de projetar e orientar uma performance (Van Dijck, 2013). Essas atuações são capazes de construir orientações que influenciam diretamente no comportamento dos usuários, tais como: a busca por popularidade (Recuero, 2009), a vaidade (Dal Bello; Rocha, 2012) e a busca por capital social (Steinfield; Ellinson; Lampe, 2008).

Iniciando pela popularidade, esta trata-se de um valor relativo à posição de um ator dentro de sua rede social e está diretamente relacionada a indicadores quantitativos característicos dessas redes, como por exemplo: número de comentários, quantidade de publicações compartilhadas, quantidades de curtidas, entre outros (Recuero, 2009). Duas características fazem das redes sociais locais ideais para indivíduos com muita necessidade por popularidade. Em primeiro lugar, as redes sociais facilitam a auto apresentação seletiva. Os usuários podem selecionar cuidadosamente imagens de perfil e autodescrições que possam torná-los mais populares. Em segundo lugar, as redes sociais facilitam a obtenção de uma grande público (amigos virtuais ou "seguidores") com apenas um clique do mouse (Siibak, 2009). Tal necessidade apresenta ainda uma relação positiva direta com a necessidade de autopromoção pessoal, inveja nas redes sociais (Utz; Tanis; Vermeulen, 2012) e autoestima (Utz; Beukeboom, 2011).

Ao ganharem popularidade, usuários comuns veem suas opiniões serem valorizadas em detrimento da posição de outros (Parmeggiani; Araújo, 2014), e dessa forma, a façanha de despertar curiosidade em outros indivíduos não se limita mais apenas às celebridades (Guimarães, 2011). A necessidade de popularidade refere-se à motivação para fazer certas coisas, a fim de parecer popular. Dessa forma, a necessidade de ser conhecido parece estar relacionada ao narcisismo, contudo, enquanto narcisistas realmente acreditam que são superiores, indivíduos com uma alta necessidade de popularidade apenas querem ser percebidos como populares (Campbell; Rudich; Sedikides, 2002). 
Como se fora a outra face de uma mesma moeda, tem-se a vaidade, que se trata de uma sensação prazerosa derivada do olhar de admiração do outro para tudo que pertence (Gikovate, 1987). Nesse contexto, a aparência torna-se elemento fundamental na interação social (Polivanov, 2014), dando espaço a outros dois conceitos pertinentes na relação entre vaidade e redes sociais: o de auto exposição (Bruno; Kanshiro; Firmino, 2010) e o de autopromoção (Buffardi; Campbell, 2008; Primo, 2009). As redes sociais estimulam a autopromoção e auto exposição através de "autobiografias", do compartilhamento de fotos e do grande número de relacionamentos superficiais, onde a quantidade de amigos muitas vezes chega aos milhares (Bauman, 2001; Buffardi; Campbell, 2008).

Outro aspecto crescente na literatura é a chamada busca por capital social. Embora o capital social seja um termo flexível com uma variedade de definições em múltiplos campos (Adler; Kwon, 2009), há consenso de que este se manifesta através de valores como confiança, reconhecimento e autoridade. Recuero (2009) relata que o diferencial das redes sociais é justamente "a emergência de tipos de capital social que não são facilmente acessíveis" fora do ambiente digital, como por exemplo, ter 200 novos amigos em poucos dias não seria uma tarefa simples fora do Facebook (ou seja, "off-line").

Para entender as relações entre redes sociais e capital social, pesquisadores têm diferenciado o tipo de relações de amizade criado nessas redes, utilizando os conceitos de laços sociais defendidos por Granovetter (1973). Um típico usuário da rede social se comunica ativamente com um pequeno grupo de amigos pelas postagens ou mensagens, indicando fortes laços com esses. Por outro lado, constroem laços fracos, à medida que seguem a maioria dos amigos de forma passiva, apenas pela visualização do feed de notícias (Burke; Marlow; Lento, 2010). Logo, as redes sociais aparecem como um potencializador do capital social, tendo em vista que é um ambiente interativo no qual um dos objetivos é a construção de laços, sejam eles fortes ou fracos (Steinfield; Ellinson; Lampe, 2008).

Em suma, o processo de engajamento e a interação dos usuários no ambiente on-line dão base para entendimento do comportamento dos consumidores na era de redes sociais. Logo, é possível dizer que as redes sociais afetam os consumidores ao mesmo tempo em que também são afetadas por eles (Ioanãs; Stoica, 2014). Contudo, o impacto dessas redes não se limita apenas aos consumidores, complementar a isso, diversos setores da economia também estão sendo impactados. Entre estes, encontra-se o setor do turismo, campo que possui uma cadeia de valor diretamente centrada nas decisões do consumidor final (Alves et al., 2009).

As mídias sociais são utilizadas pelos consumidores do turismo para diferentes finalidades, que incluem desde a busca por informação sobre destinos, atrativos e serviços turísticos, até a postagem e compartilhamento de comentários, opiniões, experiências pessoais, fotos e vídeos de viagens que posteriormente servem de informações para outros turistas (Fotis; Buhalis; Rossides, 2012). Devido à natureza experiencial dos produtos turísticos, a troca de informação entre os turistas e o compartilhamento de experiências de viagem são fundamentais para diminuir a incerteza na escolha do destino e facilitar a decisão de compra. Por não poder ser experimentado antes da viagem, a escolha por um destino turístico requer julgamentos subjetivos impactados por crenças, ideias e impressões (Machado, 2015).

Fotis, Buhalis e Rossides (2012) comprovaram que as mídias sociais são acessadas em todas as fases do processo de planejamento da viagem (antes, durante e depois), variando conforme diferentes extensões e propósitos de uso. Antes da viagem, as mídias sociais são utilizadas, sobretudo, para encontrar ideias de aonde ir e buscar informações sobre excursões e atividades de lazer. Já no decurso da viagem, são acessadas para manter-se conectado com os amigos e, em menor extensão, para buscar informações relacionadas às férias. Por último, após a viagem, para compartilhar fotos e experiências (Fotis; Buhalis; Rossides, 2012; Machado, 2015).

Entre os principais temas pesquisados relacionando turismo e redes sociais, destaca-se uma incidência nas seguintes temáticas: o impacto das mídias sociais nas decisões de viagem (Ye; Law; Gu, 2009; Sparks; Browning, 2011; Ye et al., 2011); fatores que influenciam os viajantes a compartilharem suas experiências (Yoo; Gretzel, 2008; Ribeiro et al., 2014), motivações para o uso das mídias sociais (Chung; Buhalis, 2008; Parra-López et al., 2012) e a adoção de media sociais por empresas de turismo (Hee; Lee; Law, 2012; Hays; Page; Buhalis, 2013). Contudo, é possível dizer que ainda há uma grande carência de estudos, visto que o tema é relativamente novo para a literatura (Xiang; Gretzel, 2010; Zeng; Gerritsen, 2014; Chen; Zhang, 2015).

\section{Procedimentos metodológicos}

Diante dos objetivos propostos para o presente estudo e fundamentando-se na taxonomia de classificação proposta por Vergara (2007), a presente pesquisa qualifica-se, quanto aos fins, como uma pesquisa de cunho exploratório, visto que busca identificar quais os estímulos proporcionados pelas mídias sociais frente aos 
consumidores de viagens e de que forma isso pode influenciar e propiciar o consumo. Para tal, utilizaram-se técnicas projetivas que, segundo Vieira e Tibola (2005), podem ser usadas para pesquisas exploratórias visando proporcionar entendimentos e compreensões iniciais, tais como motivações, crenças, atitudes ou sensações subjacentes sobre o problema em estudo. Quanto aos meios, classifica-se como uma pesquisa de campo, uma vez que busca aprofundar-se a respeito do fenômeno das relações entre as redes sociais e os consumidores via coleta de dados por meio de entrevistas em profundidade aplicadas junto ao público alvo da pesquisa. Dessa forma, a abordagem para responder ao questionamento de pesquisa é essencialmente qualitativa.

A escolha do público alvo deu-se de forma não probabilística feita por conveniência, adotando os seguintes critérios de elegibilidade: possuírem perfis ativos nas redes sociais, especificamente no Facebook; serem usuários com faixa etária de 15 a 34 anos, faixa na qual possui $49,8 \%$ dos internautas brasileiros (COMSCORE, 2016); e uma renda familiar mínima de $\mathrm{R} \$ 10.000,00$, o que corresponderia a indivíduos pertencentes as classes A e B conforme o IBGE (2016). Os pesquisadores entenderam que seria importante contemplar indivíduos em estratos superiores de renda, uma vez que o objeto de estudo trata diretamente da escolha de destinos turísticos, onde seria importante que o sujeito fosse capaz de imaginar, ou até mesmo conhecer, o local em pauta. O Facebook foi escolhido como a mídia social de interesse por ser voltado para a interação entre amigos, onde há um maior foco na auto apresentação como um meio de se acumular um capital social (Panger, 2014) e é a rede social que mais influência os usuários na tomada de decisão de consumo (DIGITASLBI, 2015). Além disso, o Facebook é reconhecido um canal de mídia social particularmente poderoso para construção e exibição de narrativas de identidade (Van Dijck, 2013).

Estruturalmente, a pesquisa foi dividida em duas partes. Na primeira, etapa preparatória do estudo, realizada unicamente com o objetivo de estruturar os procedimentos metodológicos a serem utilizados na técnica de pesquisa desenvolvida na etapa subsequente, buscou-se, por meio de um survey on-line, com 100 respondentes, identificar quais os destinos turísticos preferenciais do público alvo da pesquisa. Finalizado esse levantamento, na segunda etapa da pesquisa, etapa que de fato concentrou o objetivo do estudo, foram realizadas 12 entrevistas em profundidade, com uma duração média de 40 minutos cada, utilizando-se técnicas projetivas, mais especificamente, por meio da projeção de imagens.

Os 12 sujeitos selecionados foram escolhidos por possuírem o perfil de público requerido para o - estudo. Ademais, utilizou-se do método de bola de neve, no qual, os próprios entrevistados indicaram os demais entrevistados. As entrevistas foram realizadas em 2016 em uma capital do Nordeste do Brasil, local onde os pesquisadores residem e abrigam um grupo de pesquisa sobre mídias sociais e consumo. Os entrevistados foram informados sobre o tema da pesquisa e sobre as técnicas para a obtenção de dados utilizadas, autorizando que as entrevistas fossem gravadas com finalidade científica depois de reforçada a preservação do sigilo quanto à identidade individual. Para determinar o número de participantes entrevistados, adotou-se o critério de saturação teórica, critério esse que, segundo Fontanella e Junior (2012), pode ser adotado quando os elementos amostrais são suficientes, necessários e possíveis para que ocorra o pretendido adensamento teórico sobre o objeto pesquisado.

As técnicas projetivas foram utilizadas na pesquisa em dois momentos. No primeiro, considerando os três destinos turísticos apontados com preferenciais no survey realizado, foram criados três cenários fictícios compostos por imagens no qual os entrevistados foram inseridos, sendo um para cada destino (Figura 1).

Figura 1: Cenários com pontos turísticos.

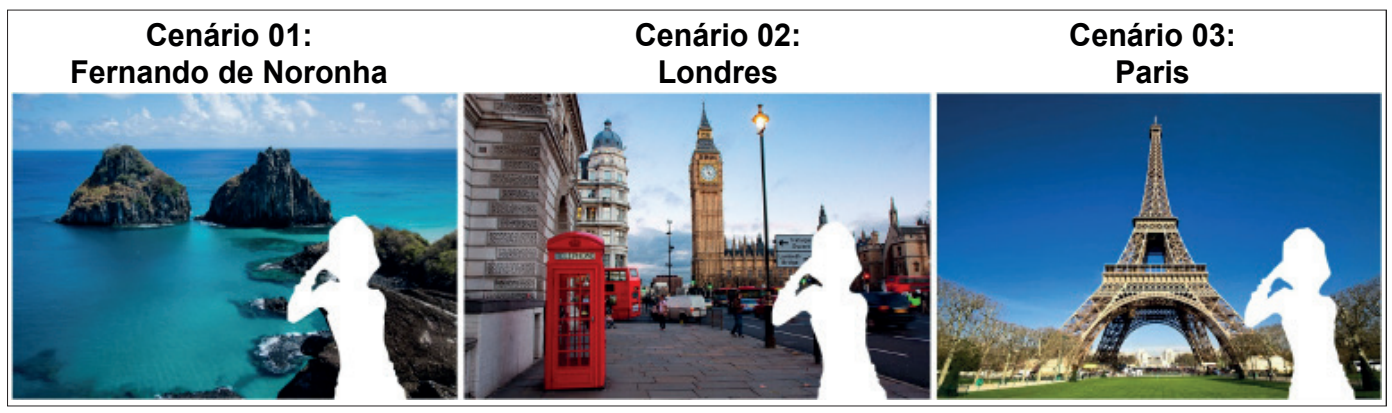

Fonte: Google Imagens; Edição: Autores. 
Nesse momento, seguindo o roteiro de entrevista, os entrevistados foram indagados sobre qual dos cenários eles compartilhariam em seu Facebook; o porquê compartilhariam o cenário escolhido e não os outros; as motivações para o compartilhamento; e os critérios de seleção da foto que seria postada. Com isso, buscou-se entender: as motivações para o compartilhamento de experiências de viagens nas redes sociais; identificar como ocorre o processo de escolha de destinos turísticos e investigar se há interferência das redes sociais nesse processo.

Na segunda etapa, visando analisar a relevância dada pelos entrevistados para os dados quantitativos das redes sociais e identificar as consequências advindas da interpretação desses dados, as técnicas projetivas foram novamente utilizadas. Assim, a foto escolhida pelo entrevistado na primeira etapa da entrevista foi inserida no contexto das redes sociais, mais precisamente na página do Facebook do entrevistado, via simulação digital utilizando-se do Adobe Photoshop CC. Com isto, buscou-se seguir as orientações de Appel, Gerlach e Crusius (2016) sobre o uso de páginas reais do Facebook para análise dos aspectos individuais dos usuáriosem pesquisa sobre mídias sociais. Assim, foram criados três novos cenários, estruturados da seguinte forma: (i) a foto escolhida para postagem no Facebook do entrevistado não possuía nenhuma curtida e nenhum comentário, exemplificado na Figura 2; (ii) a foto postada possuindo representativamente poucas curtidas e poucos comentários; (iii) a postagem da imagem possuindo representativamente muitas curtidas e muitos comentários. Para a criação dos cenários se fez necessário um estudo prévio do perfil dos pesquisado nas redes sociais, só assim tornou-se possível a criação de uma réplica do perfil dos mesmos. Reforça-se que todas as imagens utilizadas foram padronizadas em relação ao tamanho e qualidade, visando evitar que uma característica técnica interferisse na análise do respondente.

\section{Figura 2: Exemplo Cenário 01: Foto com nenhuma curtida e nenhum comentário.}

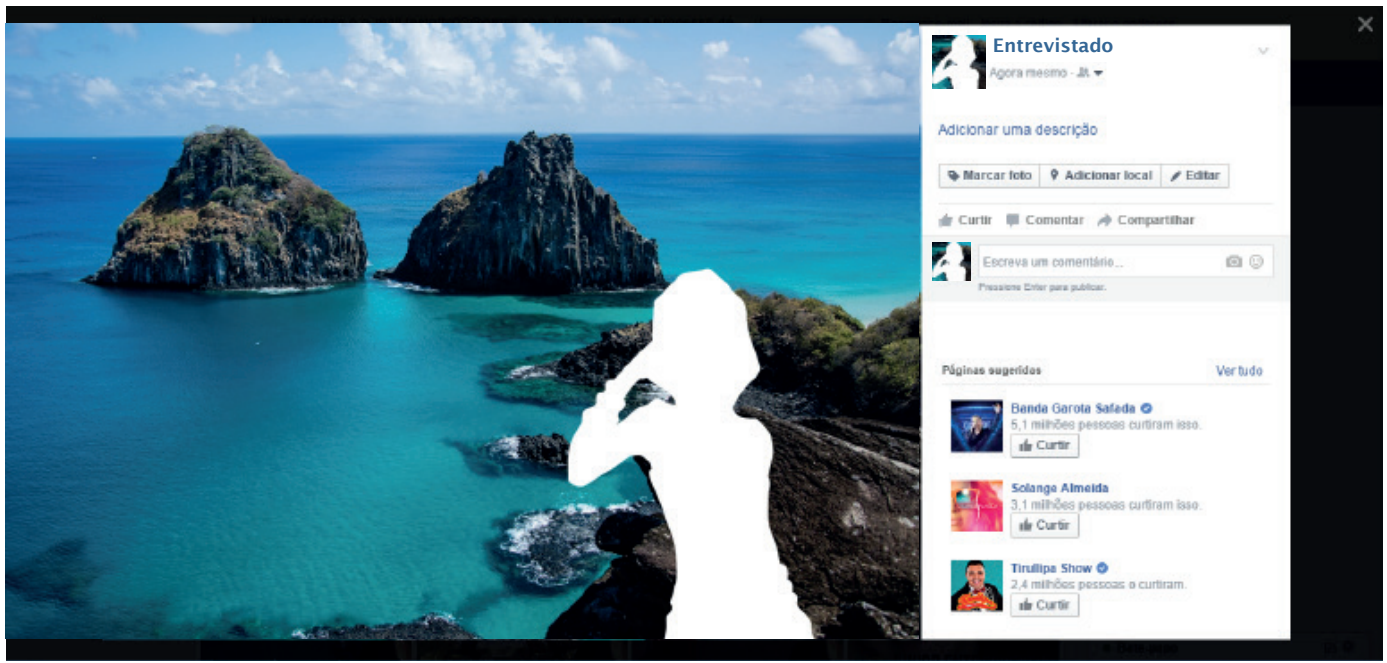

Fonte: Autores.

Os procedimentos de análise foram precedidos pela reprodução e avaliação minuciosa dos áudios e de uma detalhada transcrição do conteúdo gravado. A análise dos resultados, frutos dos procedimentos metodológicos, será apresentada na próxima seção e teve o apoio da análise de conteúdo. A análise do conteúdo foi realizada em três etapas, conforme Bardin (1977): a pré-análise, que consiste na organização do material; a exploração do material, que inicia desde a pré-análise e que é caracterizada pelos procedimentos de codificação, classificação e categorização e, por último, o tratamento dos resultados, etapa que exige a reflexão do pesquisador e o estabelecimento de inferências. Nesse contexto, as categorias teóricas do estudo foram estipuladas a partir da revisão da bibliografia. São elas: as motivações para compartilhamento, o gerenciamento da imagem na decisão de postar e as consequências do feedback. 


\section{Discussão dos resultados}

Inicialmente, conforme descrito nos procedimentos metodológicos, na etapa preparatória da pesquisa foi realizado um survey com o objetivo de identificar quais os destinos turísticos preferenciais do público alvo. Os resultados apontaram os destinos de Fernando de Noronha, Paris e Londres como os destinos mais desejados. Dessa forma, esses foram os três destinos utilizados para os procedimentos metodológicos da segunda fase da pesquisa. O Quadro 1 apresenta os códigos que serão utilizados na exposição dos resultados para identificar os sujeitos da pesquisa.

\section{Quadro 1: Identificação dos entrevistados}

\begin{tabular}{|c|c|c|}
\hline Código & Idade & Sexo \\
\hline E1-F22 & 22 anos & Feminino \\
\hline E2-M21 & 21 anos & Masculino \\
\hline E3-F24 & 24 anos & Feminino \\
\hline E4-M27 & 27 anos & Masculino \\
\hline E5-F21 & 21 anos & Feminino \\
\hline E6-M21 & 21 anos & Masculino \\
\hline E7-F24 & 24 anos & Feminino \\
\hline E8-M26 & 26 anos & Masculino \\
\hline E9-F21 & 21 anos & Feminino \\
\hline E10-M22 & 22 anos & Masculino \\
\hline E11-F22 & 22 anos & Feminino \\
\hline E12-M24 & 24 anos & Masculino \\
\hline
\end{tabular}

Assim, visando atender os objetivos propostos, os resultados da pesquisa são apresentados em três tópicos de analises: as motivações para compartilhamento, o gerenciamento da imagem na decisão de postar e as consequências do feedback.

\subsection{Motivações para o compartilhamento das experiências de viagens}

Os entrevistados foram inseridos, via projeção de imagens, em três fotos de paisagens captadas dos três destinos turísticos mais indicados na etapa preparatória da pesquisa, conforme Figura 1. Assim, foi solicitado que escolhessem entre os três, qual postariam em seu Facebook. O principal intuito nesse momento foi identificar os "porquês", tanto da escolha do destino turístico como da realização da postagem e as motivações para "repostagem", ou seja, o que motiva a continuar postando.

Quando questionados referente ao porquê da escolha do destino, analisando os discursos expostos abaixo, é notório a preocupação dos entrevistados com o ponto de vista das outras pessoas, seja na necessidade de diferenciação, como exposto na fala de E1F22, ou até mesmo na oportunidade de expor algo que pressupostamente é desejado pelos outros, conforme falas de E12M24 e E5F21.

E12M24: "Porque é chique! Estar em Londres não é para qualquer pessoa. É status, puro status!".

E5F21: "Paris, porque agrega valor e acredito ser um lugar que várias pessoas almejam ir, mas nem todas possuem condições".

E1F22: "Fernando de Noronha, porque eu acho que é mais diferente! Hoje, todo mundo vai para a Europa, todo mundo tem sua foto na Torre Eiffel e, querendo ou não, Paris é um dos lugares que as pessoas não deixam de ir quando vão para Europa. E eu acho que eu estar em Fernando de Noronha seria algo mais diferente, não seria o clichê de hoje da minha rede de relacionamentos".

Tais reflexões reforçam o que assume Belk (2016), para quem, as mídias sociais são normalmente utilizadas com o intuito melhorar a auto apresentação do indivíduo, permitindo um autogerenciamento e cocriação do "eu", fortalecendo assim, muitas vezes a uma representação mais próxima de um self 
ideal do que o próprio self. Além disso, se relacionam e corroboram, também, com os construtos de auto exposição (Bruno; Kanshiro; Firmino, 2010), autopromoção (Buffardi; Campbell, 2008; Primo, 2009) e inveja nas redes sociais (Utz; Tanis; Vermeulen, 2012), uma vez que ambos os conceitos estão relacionados com o julgamento do olhar do próximo.

Ao serem questionados sobre os motivos de realizarem suas postagens e compartilharem suas experiências de viagens nas redes sociais, a busca por popularidade apareceu como um fator motivador dessa decisão. Tal constatação pode ser observada nas falas abaixo, e é embasada teoricamente via Recuero (2009), para quem, em contexto de redes sociais, o construto popularidade está diretamente relacionado aos indicadores quantitativos característicos desses tipos de redes. Além disso, é fortalecida quando se retoma as pesquisas de Campbell, Rudich e Sedikides, (2002) e Guimarães (2011), para quem a necessidade de popularidade refere-se à uma motivação para fazer certas coisas, a fim de parecer popular e visar a façanha de despertar curiosidade em outros indivíduos.

E12M24: "Ninguém viaja só por viajar, as pessoas viajam para postar uma foto e para serem curtidas". E9F21: "Mostrar o que estou vivendo no momento e eu acho que isso motiva outras pessoas a quererem viajar também".

E6M21: "Eu quero que as pessoas participem um pouco do que eu participo. Além disso tem uma questão que nas redes sociais você quer mostrar algo para alguém, então, é uma questão de status também. A verdade é essa".

Para além do ato inicial de postar, os entrevistados também foram indagados sobre quais fatores incentivam a continuidade da postagem. Nesse contexto, o feedback positivo da foto inicialmente postada, ou seja, a fato de ter uma boa repercussão nas redes sociais, repercussão essa fortemente avaliada pelo indicador de curtidas, no ponto de vista dos entrevistados, caracteriza-se como uma forma de aprovação dos demais membros da sua rede de relacionamento e os incentivam a continuar compartilhando.

E1F22: "O que é curtir? É você dizer que você gostou de alguma coisa que a outra pessoa está colocando, então se eu posto uma foto e tem muitas curtidas e várias pessoas gostam, significa que se interessam pelo conteúdo que estou colocando, então queira ou não, é um incentivo".

No discurso exposto por E1F22, é possível constatar a valorização das curtidas como uma forma de reconhecimento da aprovação do olhar do outro, logo, considerando a concepção de Simon (2004), tal feedback interfere no self de quem realiza a postagem, uma vez que, o self é o resultado de um processo de autorreflexão, à medida que o indivíduo se torna um objeto significativo para ele mesmo ao observar sua reflexividade a partir do ponto de vista do outro.

Assim, foi possível notar a expressão de diferentes motivações, tais como: a busca por status, a vontade de diferenciação dentro da própria rede de relacionamento, desejo de exibir conquistas e despertar curiosidade no próximo e a busca por popularidade, como motivações para o compartilhamento da experiência de viagens nas redes sociais. Como pode ser visto estas motivações vão além daquelas identificadas por Ramanathan e McGill (2007) e Zauberman, Ratner e Kim (2009), que apresentam a preservação da memória de um momento vivido e o compartilhamento de experiências com os amigos como fatores motivadores do compartilhamento. Além disso, para o ramo do turismo, tais motivações corroboram com os estudos de Yoo e Gretzel (2008), Chung e Buhalis, (2008), Parra-López et al. (2012) e Ribeiro et al. (2014).

\subsection{O gerenciamento da imagem na decisão de postar}

Após apresentado no tópico anterior as motivações para postagem, nessa seção o principal objetivo é explorar o que acontece entre o momento que a foto é registrada e o momento que a foto é postada/ divulgada. Logo, os questionamentos da pesquisa buscaram identificar quais são os filtros e ponderações utilizadas para a definição de qual foto será postada para compartilhar as experiências de viagens.

Conforme exposto nas falas abaixo, a vaidade e auto gerenciamento de imagem podem ser considerados como fatores interveniente para o compartilhamento de experiências de viagens. O "estar belo" destaca-se como uma das maiores preocupações dos usuários nesse processo decisório, corroborando com as afirmações de Polivanov (2014), para quem a aparência destaca-se como elemento fundamental na interação social, e de Barasch, Diehl e Zauberman (2014) ao referir-se sobre a preocupação do indivíduo com o auto gerenciamento da imagem. Isso relaciona-se ainda com os escritos de Belk (2016), visto que o critério da beleza pode ser considerado também como um fator determinante da decisão entre revelar o "eu" apropriado ou esconder o self indesejado. 
E7F24: "Eu posso tirar uma foto em um lugar lindo e famoso, mas se eu não tiver saído legal na foto penso muito se postarei ou não, pois eu preferiria postar uma foto em que os dois estivessem bonitos, eu e o local". E8M26: "Seria a combinação se eu estou bem na foto com a paisagem. No caso de um ponto turístico, se eu tirar uma foto e ficar legal, eu posto, se eu não sair bem eu posto a foto somente do local”.

E4M27: "A beleza da foto, se eu saio bonito ou feio, além das companhias e o momento em que a foto foi tirada". E11F22: "Eu na foto, como eu fico, e o lugar também, se for uma foto boa. Sabe, aquelas fotos que você não precisa colocar muito efeito para ficar boa? E eu olho para mim também”.

Quando questionados sobre o porquê os fatores citados acima são importantes na ponderação da foto a ser postada nas redes sociais, a necessidade de aprovação do próximo foi fortemente identificada. Assim, é possível identificar a importância das redes sociais enquanto meio de os indivíduos construírem sua identidade, uma vez que, retomando o conceito de Baumam (2005), a identidade se apresenta como um meio de comunicação do self para o mundo exterior, e precisa da aprovação do outro para se estabelecer de forma bem-sucedida. Essa necessidade de aprovação pelo próximo é expressada pelos entrevistados nos recortes abaixo:

E8M26: "Seria pela questão dos likes".

E2M22: "O estar bem na foto é porque não vou postar uma foto que estou feio, ne? \{risos\}".

E11F22: "Eu gosto de postar fotos bonitas, eu gosto de postar fotos em que as pessoas vejam realmente a beleza do lugar".

E1F22: "Eu gosto que alguém olhe e diga assim: 'Uau, que lugar lindo! Que experiência!' Porque eu acho assim, o dia a dia das pessoas não difere muito, e tipo, quando você vai compartilhar alguma coisa com alguém, você quer mostrar alguma coisa da sua vida que foi diferente, que foi 'excepcional', então, para mim, o fato de uma foto 'Uau'é o que quero compartilhar".

Nesse contexto, o posicionamento dos entrevistados nessa etapa da pesquisa reforça a atuação das redes sociais como suportes digitais para melhorar a auto apresentação do indivíduo e permitir um autogerenciamento e cocriação do "eu”, tornando esses indivíduos mais propensos a incorporar "novos eus" como parte de si mesmo, impactando assim, diretamente no processo de construção de sua identidade, fortalecendo dessa forma as concepções de Bauman (2005) e Belk (2016).

\subsection{As consequências do feedback ("Curtir" e "Comentar")}

É no retorno do olhar do próximo, no julgamento do self, que as emoções e as atitudes aparecem. Assim, as ações como "Curtir" e "Compartilhar", características das redes sociais, conforme exposto nas seções anteriores, exercem um papel importante nesse julgamento que despertam tanto emoções positivas como emoções negativas. Dessa forma, a presente seção de análise tem como objetivo identificar a importância desses indicadores para os usuários de redes sociais visando entender as consequências que tal julgamento desperta no indivíduo.

Logo, para identificar a importância desses indicadores, os entrevistados foram apresentados a três cenários, conforme apresentados na metodologia, onde o fator que diferenciava um do outro era a repercussão que a foto tinha nas redes sociais, ou seja, o número de curtidas e comentários. O cenário com mais curtidas foi o mais escolhido entre os pesquisados. Isso reforça que as redes sociais estimulam a autopromoção e auto exposição através do compartilhamento de fotos e do grande número de relacionamentos superficiais, onde a quantidade de amigos muitas vezes chega aos milhares (Bauman, 2001; Buffardi; Campbell, 2008). Assim, quando questionados o porquê dessa escolha, conforme exposto abaixo, os motivadores variaram desde a necessidade de aprovação dos outros (Siibak, 2009), até o impacto direto na autoestima (Utz; Beukeboom, 2011).

E1F22: "Porque faz bem para a autoestima quando muitas pessoas curtem uma foto sua. Embora, muitas vezes não seja verdade que as pessoas comentam, mas você se sente bem. É bom às vezes você ver que alguém gostaria de estar no seu lugar naquele momento. Por isso, quando estou viajando, e sei que vou bater uma foto, eu saio mais arrumada do que o normal, porque sei que vou bater uma foto, então assim, é como se fosse a valorização de um esforço também".

E2M21: "Acho que, se mais pessoas gostaram da minha foto, melhor. É importante você saber que as pessoas gostaram de algo que você fez, ou que você falou".

E6M22: "Porque significaria que mais pessoas tinham visto, mais pessoas tinham gostado, e na realidade, quando você compartilha uma coisa na Internet é porque você quer ser notado. Se fosse uma coisa para ninguém curtir, para ninguém ver, você não iria postar, e sim guardar no seu computador”. 
As falas acima trazem à tona também o tipo de relações estabelecidos no ambiente de redes sociais on-line, os laços fortes e laços fracos. Observa-se que os próprios usuários reconhecem, indiretamente, a presença dos dois tipos de "laços", conforme constatado na fala de E1F22, quando relata que "Embora, muitas vezes não seja verdade que as pessoas comentam". Tal constatação lança luz à relação entre capital social e redes sociais, uma vez que o capital social nas redes sociais se manifesta através de reconhecimentos que não são facilmente acessíveis no mundo off-line (Recuero, 2009).

Quando questionados se as curtidas e comentários eram fatores importantes para eles, os entrevistados forneceram respostas positivas e com tais foi possível identificar novamente a busca por popularidade como um sentimento fortalecido, confirmando os construtos de Recuero (2009) e Siibak (2009).

E12M24: "Acredito que sim! É sinal que estou sendo visto e que as pessoas estão gostando".

E1F22: "Sim. É, porque me faz sentir valorizada".

E9F21: "Eu gosto. Eu procuro realmente de vez em quando postar uma foto que eu acho que vai dar mais curtida. Normalmente eu não posto foto de qualquer coisa".

Tais sentimentos talvez justifiquem o fato de nenhum entrevistado ter escolhido o cenário no qual a foto postada não tinha nenhuma curtida. Em relação a esse cenário, o sentimento de recusa foi predominante. Identificou-se, portanto, que as pessoas, indiretamente, já esperam uma quantidade mínima de curtidas independentemente do tipo de foto postada e, quando isso não acontece, os usuários se sentem incomodados. Esse incômodo estimula questionamentos que levam os usuários a uma reflexão dos "porquês" de a repercussão desejada não ter sido alcançada. Nesse contexto, muitos buscam encontrar algum tipo de equívoco ou defeito nas postagens e, em alguns casos, isso pode até mesmo conduzi-los a exclusão da postagem, conforme falas abaixo:

E7F24: "Geralmente em dez a vinte minutos têm pelo menos uma curtida e já teve vezes, em horários, que eu atualizei e não teve nenhuma curtida. Eu acho estranho, porque geralmente qualquer pessoa tem pelo menos uma curtida em vinte, trinta minutos".

E10M22: "Há algo de errado! Eu ia achar estranho, porque geralmente, alguém, nem que seja só os amigos próximos, sempre comentam e curtem. Eu iria revisar a foto. Acho que eu ia perguntar para alguém os motivos".

E12M24: "Eu apago! Porque ninguém está vendo, ninguém está gostando, para que estará lá?".

E9F21: "Eu excluo. Porque eu já fiz isso! Excluo mesmo, porque aí eu fico para mim, sabe? Tipo, eu fico revendo a foto mil vezes e começo achar defeitos, aí eu apago".

Para reforçar a influência das redes sociais no consumo de viagens, os entrevistados foram questionados se já haviam viajado para algum lugar pensando na foto que iriam compartilhar em suas redes sociais. Unanimemente, todos os entrevistados afirmaram que sim. Analisando o discurso de E1F22 abaixo, nota-se o reforço da segmentação proposta pela pesquisa Amadeus (2017), que defende que já é significativo o segmento de viajantes que irão comprar e consumir experiências de viagens quase que inteiramente baseadas em quão compartilháveis elas são, ou quanto "capital" elas gerarão por meio das redes sociais.

E1F22: "Eu não estava gostando muito das fotos que eu estava batendo, ai, eu estava até com minha família, tipo, eu desci, me ajeitei todinha, ajeitei até a maquiagem para bater uma foto descente, assim, que eu gostasse, e fiquei lá até bater uma foto que eu tivesse gostado. No final, eu lembro que a foto que eu postei eu nem tinha amado, mas eu estava determinada a postar uma foto naquele lugar, então, eu postei! ”.

Quando questionados sobre o que esperavam que acontecesse nas redes sociais quando postassem a foto, obteve-se um reforço empírico a esse novo segmento de viajantes, tendo em vista que a busca por um capital social (Steinfield; Ellinson; Lampe, 2008) foi identificada nas falas dos entrevistados abaixo.

E12M24: "Eu esperava vários comentários, e de fato foi, um monte de gente comentando e curtindo, tipo 'aí, que legal"'.

E3F24: "É eu achei que as pessoas iam achar engraçado, tipo a pose e tal... curtidas eu sabia que ia ter, porque quando você tira foto em viagens, sempre têm! ".

E1F22: "Eu achava que ia ter curtidas, mas que não ia ser minha Top foto de curtida, porque eu já não estava gostando muito da foto. Mas, assim, que as pessoas falassem assim, "aí, que legal, essa cidade é muito legal”, esses comentários que as pessoas sempre colocam. E foi o que de fato aconteceu”. 
Como consequência do "capital" gerado, os entrevistados acreditam que, de forma direta ou indireta, conforme fala de E3F24 abaixo, as suas postagens de viagens no Facebook despertam desejos em seus amigos em conhecer os locais que foram compartilhados, gerando assim, uma influência sobre os mesmos. E3F24: "Com certeza, pelo que já me falaram sabe, tipo, 'aí amiga, vi tua foto não sei aonde, eu preciso ir lá' Então muitos lugares acabam que entram na lista de outras pessoas".

Reforça-se ainda nesse contexto o poder de "viralização" das redes sociais, mostrando que, a influência das redes sociais impacta não somente o ciclo de amizade do usuário que posta, mas também os amigos em comum a ele, de forma que, torna-se quase impossível mensurar quantitativamente o impacto da postagem.

A intercessão dos três tópicos de analises supracitados revelam os resultados empíricos coletados nesta pesquisa, de natureza exploratória, que, em diferentes aspectos corroborou com achados de pesquisas anteriores, assim como, trouxe indagações complementares, ainda pouco exploradas na área de comportamento do consumidor e redes sociais, e que lançam sementes para futuras pesquisas. Em suma, os achados da pesquisa sugerem que, para além do âmbito da informação, as mídias sociais de forma geral e, mais especificamente, em um contexto de viagem, são capazes de exercer influências diretas e indiretas aos seus usuários. Dessa forma, o estudo compreendeu que as redes sociais surgem cada vez mais como mediadoras da construção de identidade, uma vez que se reforçam como suportes digitais para melhorar a auto apresentação do indivíduo e permitir um autogerenciamento e cocriação do "eu".

\section{Considerações finais}

Embora trate-se de uma pesquisa exploratória, a análise do campo trouxe evidências empíricas embrionárias que apontam para uma possível compreensão das relações existentes entre as redes sociais e o consumo. Aprofundando-se no campo do turismo, o estudo objetivou compreender de que forma o consumo de destinos turísticos é influenciado pela interação e compartilhamento de experiências que ocorre nas redes sociais. Tal constatação ainda é pouco explorada nas pesquisas realizadas até então e com o presente trabalho pretendeu-se iniciar uma discussão a este respeito.

A pesquisa de campo mostrou evidências de que o compartilhamento de experiência de viagens nas redes sociais está relacionado com diferentes fatores motivacionais que impactam diretamente no comportamento de seus usuários, corroborando assim com estudos já existentes na literatura. Dessa forma, ao explorar o que os viajantes almejam ao compartilharem suas experiências de viagens com outros usuários das redes sociais, a necessidade de aprovação do self, a busca por popularidade e o desejo de auto exposição aparecem como fatores motivadores para o compartilhamento de experiências, sendo a vaidade uma característica pessoal que potencializa esta relação.

Um dos achados relevantes do estudo, demonstra que o fato de compartilhar uma foto nas redes sociais gera nos seus usuários uma expectativa de retorno ou repercussão da mesma, via curtidas e comentários, que é capaz de despertar nesses usuários emoções antagônicas, que vão desde felicidade, quando há uma repercussão positiva das experiências compartilhadas, até o sentimento de tristeza e decepção, quando as evidências sobre a aprovação não acontecem. Além disso, essa expectativa criada é composta também pelo fator tempo, ou seja, o tempo decorrido entre a postagem da foto e o início da reação dos amigos, quanto maior o espaço entre esses dois fatores maior o sentimento de frustração e não aprovação, acarretando em alguns casos até a exclusão da foto postada. Quando a repercussão é positiva, o quem curte e porquê curte torna-se um fator potencializador do sentimento de aprovação, assim, constatou-se que, a análise da repercussão positiva leva em consideração não somente a quantidade, muitas vezes estimuladas por laços fracos contidos nessas redes, mas também a qualidade, ou seja, há uma necessidade de conhecer quem curtiu ou comentou de forma a ponderar a importância de tal curtida ou comentário. Dessa forma, evidencia-se a busca por popularidade e a busca por capital social como fortes inerentes na intenção de compartilhar experiências de viagem.

O estudo sugere que o processo de viagem é impactado pelas influências das redes sociais não somente no âmbito da informação. Assim, respondendo a uma das dúvidas motivadoras da pesquisa, o campo mostra que, para a escolha do destino turístico, os usuários muitas vezes projetam-se previamente no destino de forma a imaginar a foto que irá postar em suas redes, logo, é possível aludir que há sim uma ponderação acerca da possibilidade de compartilhar experiências de viagens nas redes sociais na escolha do destino turístico. 
Em termos de implicação metodológica, pontua-se como fator a ser indicado para outros pesquisadores interessados no comportamento de usuários de redes sociais, a importância de colocar o indivíduo dentro de perfis reais da rede escolhida. A possibilidade de conversar com o usuário, ao mesmo tempo que ele apresentava a sua própria página do Facebook, facilitou sobremaneira o diálogo que foi construído no decorrer da coleta de dados.

Registra-se que o comportamento do usuário foi estudado em uma perspectiva individual, sem considerar o possível efeito de comparação entre grupos, como aqueles que podem ser formados dentro do Facebook. Pesquisas posteriores poderiam tentar compreender melhor o efeito do grupo neste fenômeno. Além disto, em estudos futuros, há a oportunidade de compreender em que medida as experiências anteriores e as valorações dos indivíduos impactam no fenômeno observado. Tais julgamentos podem ter influência nos resultados psicológicos e comportamentais do processo de consumo, a partir das experiências prévias, do envolvimento e da importância que os indivíduos dão ao objeto de estudo.

\section{Bibliografia}

Adler, P.S.; Kwon, S.

2009. Social Capital: Prospects for a New Concepts. The Academy of Management Review, v. 27(1): 17-40. Alves, S.; Júnior, L.F.O.V.; Vaz, L.F.H., Salomão, R./

2009. "Cenários para a Indústria de Turismo e Viagens - Um Ecossistema em Transformação”. Encontro Nacional da Associação Nacional dos Programas de Pós-Graduação em Administração (Anpad), 33. São Paulo/SP.

Amadeus.

2017. Future Traveller Tribes 2030: entendendo o viajante do futuro. Disponível em: < http://www. amadeus.com/tribes2030 >. Acesso em: 20 de abril de 2017.

Appel, H.; Gerlach, A.L.; Crusius, J.

2016. "The interplay between Facebook use, social comparison, envy, and depression." Current Opinion in Psychology, 9 (3): 44-49.

Bardin, L.

1977. Análise de conteúdo. Lisboa: Edições 70.

Bauman, Z.

2005. Identidade. Rio de Janeiro: Jorge Zahar.

Barasch, A.; Diehl, K.; Zauberman, G.

2014. When Happiness Shared is Happiness Halved: How Taking Photos to Share with Others Affects Experiences and Memories. Advances in Consumer Research, v. 42: 130.

Belk, R.

1998. Possessions and the Extended Self. The Journal of Consumer Research, 15: 139-168.

Belk, R.

2016. Extended self and the digital world. Current Opinion in Psychology, 10: 50-54.

Boyd, D.M.; Ellison, N.B.

2008. Social network sites: definition, history, and scholarship. Journal of Computer-Mediated Communication, 13(1): 210-230.

Brown, J.; Broderick, A.J.; Lee, N.

2007. Word of mouth communication within on-line communities: Conceptualizing the on-line social network. Journal of Interactive Marketing, 21 (3): 2-20.

Bruno, F.; Kanashiro, M.; Firmino, R.

2010. (Orgs). Vigilância e visibilidade: espaço, tecnologia e identificação. Porto Alegre: Sulina.

Buffardi, L.E.; Campbell, W.K.

2008. Narcissism and Social Networking Web Sites. Personality and Social Psychology Bulletin, 34 (10): 1303-1314.

Burke, M., Marlow, C.; Lento, T.

2010. Social network activity and social well-being. Postgraduate Medical Journal, 85: 455-459.

Camargo, L.O.L.; Solbiati, P.P.; Péccora, F.C.; Pinheiro, N.O.

2016. Blogs de viagem e a decisão final do turista. Revista Rosa dos Ventos - Turismo e Hospitalidade, 8(2): 205-221. 
Campbell, W.K.; Rudich, E.A.; Sedikides, C.

2002. Narcissism, self-esteem, and the positivity of self-views: Two portraits of self-love. Personality \& social psychology bulletin, 28 (3): 358-368.

COMSCORE.

2016. Brazil Digital Future in Focus. Disponível em: http://agenciamarketing digital.net/blog/2014_Brazil_Digital_Future_in_Focus_PT.pdf. Acesso em: 13/01/2016.

Chen J.; Zhu, Z.; Xie, H.Y.

2004. Measuring intellectual capital: a new model and empirical study. Journal of Intellectual Capital, 5 (1): 195-212.

Chen, X; Zhang, H.

2015. The Use of Social Media in Tourism: A Literature Review. Tourism Tribune, 30 (8): 35-43.

Chung, J.Y.; Buhalis, D.

2008. Information needs in online social networks. Information Technology \& Tourism, 10: 267-281.

Dal Bello, C.; Rocha, D.C.

2012. Visibilidade mediática, vigilância e naturalização do desejo de autoexposição. XXI Encontro Anual da Compós. Anais.

Digitalbi.

2015. Connected Commerce. Disponível em:<http://www.digitaslbi.com/Global/ Connected Commerce2015-Deck-FINAL.pdf>. Acesso em: 24 de novembro de 2015.

Fontanella, B.J.B.; Júnior, R.M.

2012. Saturação teórica em pesquisas qualitativas: Contribuições psicanalíticas. Psicologia em Estudo, 17 (1): 63-71.

Fotis, J.; Buhalis, D.; Rossides, N.

2012. Social Media Use and Impact during the Holiday Travel Planning Process. In: Fuchs M., Ricci F., Cantoni L. (eds) Information and Communication Technologies in Tourism. Springer, Viena.

Gikovate, F.

1987. Vício dos Vícios: um Estudo sobre a Vaidade Humana. São Paulo: MG Editores Associados: 154p. Granovetter, M.

1973. The strength of weak ties. American Journal of Sociology, 78: 1360-1380.

Guimarães, T.

2011. O paradoxo da intimidade publicizada: a visibilidade contemporânea no site da rede social Facebook. Dissertação de mestrado em ciências da comunicação - Faculdade de Ciências Sociais e Humanas. Universidade Nova Lisboa, Lisboa, Portugal.

Hays, S.; Page, S.J.; Buhalis, D.

2013. Social media as a destination marketing tool: Its use by national tourism organisations. Current Issues in Tourism, 16(3), 211-239.

Hee, D.L.; Lee, A.; Law, R.

2012. Examining hotel managers' acceptance of web 2.0 in website development: A case study of hotels in Hong Kong. In M. Sigala, E. Christou, \& U. Gretzel (Eds.), Social media in travel, tourism and hospitality: Theory, practice and cases (pp. 53-65). Surrey, UK: Ashgate.

Hu, K-C.; Lu, M.; Huang, F-Y.; Jen, W.

2016. Click "Like" on Facebook: The Effect of Customer-to-customer Interaction on Customer Voluntary Performance for Social Networking Sites. International Journal of Human-Computer Interaction, 7318: 1-8.

Ioanãs, E.; Stoica, I.

2014. Social Media and its Impact on Consumers Behavior. International Journal of Economic Practices and Theories, 4 (2): 295-303.

Kaplan, A.M.; Haenlein, M.

2010. Users of the world, unite! The challenges and opportunities of social media. Business Horizons, 53 (1): 59-68.

Keen, Andrew

2007. O Culto do Amador: Como blogs, MySpace, Youtube e a pirataria digital estão destruíndo nossa economia, cultura e valores. Zahar, Rio de Janeiro

Kietzmann, J. H.; Hermkens, K.; Mccarthy, I. P.; Silvestre, B. S.

2011. Social media? Get serious! Understanding the functional building blocks of social media. Business Horizon, 54 (3): 241-251. 
Ladik, D.; Carrillat, F.; Tadajewski, M.

2015. Belk's (1988) "Possessions and the extended self" revisited. Journal of Historical Research in Marketing, 7: $184-207$.

Lin, N.

1999. Social Networks and Status Attainment. Annual Review Sociology, 25: 467-87.

Machado, D.F.C.

2015. Fotografias de viagens nas redes sociais : um estudo sobre os efeitos da visualização de fotografias na imagem do destino e na intenção futura de visita. 233f. Tese (Doutorado em Administração) Universidade Federal do Rio Grande do Sul, Porto Alegre.

O'Reilly, T.

2007. What Is Web 2.0: Design Patterns and Business Models for the Next Generation of Software. Design, 65: 17-37.

Oliveira, G.C.; Frossard, M.S.

2017. A sociedade do espetáculo e o ato de fotografar nas viagens. Revista de Turismo y Patrimonio Cultural, 15: 261-272.

Recuero, R. D. C.

2009. Redes Sociais na Internet. Porto Alegre: Sulina.

Ribeiro, H., Amaro, S., Seabra, C., Abrantes, J.L.

2014. Travel content creation: The influence of travelers' innovativeness, involvement and use of social media. Journal of Hospitality and Tourism Technology, 5(3): 245-260.

Pan, B.; Maclaurin, T.; Crotts, J.C.

2007. Travel Blogs and the Implications for Destination Marketing. Journal of Travel Research, 46: 35-45. Panger, G.

2014. Social comparison in social media: a look at facebook and twitter. In: CHI'14 Extended Abstracts on Human Factors in Computing Systems. ACM: 2095-2100.

Parmeggiani, B.; Araújo, B.

2014. Os heavy users e suas publicações no Facebook: um estudo sobre imagem, visibilidade e celebridade na rede. VIII Simpósio Nacional da ABCiber. Anais. São Paulo.

Parra-López, E.; Gutiérrez-Taño, D.; Díaz-Armas, R. J.; Bulchand-Gidumal, J.

2011. Travellers 2.0: Motivation, opportunity and ability to use social media. In M. Sigala, E. Christou, e U. Gretzel. Social media in travel, tourism and hospitality: Theory, practice and cases (pp. 171-187). Surrey, UK: Ashgate.

Patrocínio, R.F.A.

2012. Comunicação Boca a Boca nas Redes Sociais e seu Impacto no Comprometimento Afetivo do Cliente. 92f. Dissertação (Mestrado em Administração) - Universidade FUMEC, Belo Horizonte.

Phau, I.; Lo, C-C.

2004. Profiling fashion innovators: A study of self-concept, impulse buying and Internet purchase intent. Journal of Fashion Marketing and Management, Bradford, 8 (4): 399- 411.

Phelan, K.V.; Chen, H. T.; Haney, M.

2013. "Like" and "Check-In": how hotels utilize Facebook as an effective marketing tool. Journal of Hospitality and Tourism Technology, 4 (2): 134- 154.

Pinto, M.A.A.

2016. Influência das redes sociais na perceção e escolha de um destino. 80 f. Dissertação (Mestrado em Marketing Digital). Lisboa: Universidade Europeia.

Polivanov, B.B.

2014. Fazendo faxina no Facebook: implicações do gerenciamento e comunicação com a Rede de Contatos para Dinâmicas de Autoapresentação. Revista de Estudos da Comunicação, 15 (38): 353- 369.

Primo, A.

2009. A busca por fama na web: reputação e narcisismo na grande mídia, em blogs e no Twitter. Anais do XXXII Congresso Brasileiro de Ciências da Comunicação. Anais... Curitiba/PR.

Ramanathan, S.; Mcgill, A.L.

2007. Consuming with others: Social influences on moment-to-moment and retrospective evaluations of an experience. Journal of Consumer Research, 34 (4): 506-524.

Sacchet, R.O.F.; Loureiro, O.; Ferreira, M.V.M.; Willrdin, I.A.V.; Filho, V.A.V.

2011. Comportamento Caótico Do Consumidor Na Era Digital: Uma Abordagem Baseada Na Teoria Do Caos. Revista de Administração da UNIMEP, 9 (3): 87- 111. 
Schiffman, L.G.; Kanuk, L.L.

2000. Comportamento do consumidor. 6. ed. Rio de Janeiro, RJ: LTC.

Schultz, C.D.

2016. Insights from consumer interactions on a social networking site: Findings from six apparel retail brands. Electronic Markets, 26 (3): 203- 217.

Serafim, D.; Mendes, L.; Corrêa, C.

2017. Comentários de Viagem na Internet: Fatores que influenciam a intenção de escolha de um destino de viagem. Revista de Turismo y Patrimonio Cultural, 15: 229-244.

Siibak, A.

2009. Constructing the self through the photo selectionvisual impression management on social networking websites. Cyberpsychology: Journal of Psychosocial Research on Cyberspace, 3 (1).

Simon, B.

2004. Identity in Modern Society. A social psychology perspective. Oxford: Blackwell Publishing: 20-24.

Smith, M.; Barash, V.; Getoor, L.; Lauw, H.W.

2008. Leveraging social context for searching social media. Proceedings of the 2008 ACM workshop on search in social media. ACM: 91-94.

Sousa, P.V.; Braga, V.

2013. Self, Identidade, redes sociais: definições e relações entre a psicologia social e a comunicação em tempos de redes sociotécnicas. $7^{\circ}$ Simpósio Nacional da Associação Brasileira de Cibercultura. Anais. Curitiba, Paraná.

Sparks, B.A.; Browning, V.

2011. The impact of online reviews on hotel booking intentions and perception of trust. Tourism Management, 32(6): 1310-1323.

Steinfield, C.; Ellison, N.; Lampe, C.

2008. Social Capital, self-esteem, and use of online social network sites: a longitudinal analysis. Journal of Applied Developmental Psychology, 29 (5): 434-445.

Stephen, A.T.

2016. The role of digital and social media marketing in consumer behavior. Current Opinion in Psychology, 10: 17-21.

Tubenchlak, D.B.

2013. Fatores motivacionais da comunicação boca- a-boca eletrônica positiva entre consumidores no Facebook. 129f. Dissertação (Mestrado em Administração) - Fundação Getúlio Vargas, Rio de Janeiro. Utz, S., Beukeboom, C.

2011. The role of social network sites in romantic relationships: Effects on jealousy and relationship happiness. Journal of Computer-Mediated Communication, 16: 511- 527.

Utz, S.; Tanis, M.; Vermeulen, I.

2012. It Is All About Being Popular: The Effects of Needfor Popularity on Social Network Site Use. Cyberpsychology, Behavior, And Social Networking, 15 (1): 37-42.

Van Dijck, J.

2013. "You have one identity": performing the self on Facebook and Linkedin. Media Culture \& Society, 35, 2: 199-215.

Vergara, S.C.

2007. Projetos e relatórios de pesquisa em administração. Atlas, 8. ed. São Paulo/SP.

Vieira, V.A., Tibola, F.

2005. "Pesquisa qualitativa em marketing e suas variações: trilhas para pesquisas futuras". Revista de Administração Contemporânea. 9 (2): 9-33.

Xiang, Z.; Gretzel, U.

2010. Role of social media in online travel information search. Tourism Management, 31(2): 179-188.

Ye, Q.; Law, R.; Gu, B.

2009. The impact of online user reviews on hotel room sales. International Journal of Hospitality Management, 28(1): 180-182.

Ye, Q.; Law, R.; Gu, B.; Chen, W.

2011. The influence of user-generated content on traveler behavior: An empirical investigation on the effects of e-word-of-mouth to hotel online bookings. Computers in Human Behavior, 27(2): 634-639. Yoo, K.-H.; Gretzel, U.

2008. What motivates consumers to write online travel reviews? Information Technology \& Tourism, 10 (4): 283-295. 
Zauberman, G.; Ratner, R.K.; Kim, B. K.

2009. Memories as assets: Strategic memory protection in choice over time. Journal of Consumer Research, v. 35 (5): 715-728.

Zeng, B., Gerritsen, R.

2014. "What do we know about social media in tourism? A review". Tourism Management Perspectives, 10: 27-36. 